\title{
Potencial Alelopático de Panicum maximum JACQ sobre a Germinação de Sementes de Espécies Nativas
}

\author{
Danielle Medina Rosa ${ }^{1}$, Andréa Maria Teixeira Fortes ${ }^{2}$, \\ Márcia Maria Mauli ${ }^{1}$, Denise Sommer Marques ${ }^{3}$, Denise Palma ${ }^{1}$ \\ ${ }^{1}$ Laboratório de Análises de Sementes e Plantas, Universidade Estadual do Oeste do Paraná - UNIOESTE \\ ${ }^{2}$ Laboratório de Fisiologia Vegetal, Universidade Estadual do Oeste do Paraná - UNIOESTE \\ ${ }^{3}$ Universidade Estadual Paulista - UNESP
}

\section{RESUMO}

Neste trabalho testou-se o efeito do extrato de capim colonião (Panicum maximum) sobre a germinação de sementes de alface, canafístula e angico. Os extratos foram elaborados na proporção de $200 \mathrm{~g}$ de parte aérea fresca e $100 \mathrm{~g}$ de parte aérea seca para cada litro de água destilada, resultando no extrato bruto (100\%), sendo diluído para as concentrações de 20, 40, 60 e $80 \%$. O extrato de capim colonião prejudicou a germinação de sementes de alface, porém, nas sementes de espécies nativas estudadas, o único efeito observado foi estimulatório. Dessa forma, o efeito exercido sobre as espécies nativas na Estrada do Colono do Parque Nacional do Iguaçu não deve ser alelopático, atribuindo-se a outros efeitos, como competição.

Palavras-chave: alelopatia, Peltophorum dubium (Spreng.) Taub, Parapiptadenia rigida (Benth.) Brenam.

\section{Allelophatic Potential of Panicum maximum JACQ on Native Species Seed Germination}

\begin{abstract}
This study tested the effect of the extract of Panicum maximum on lettuce, Peltophorum dubium (Spreng.) Taub and Parapiptadenia rigida (Benth.) Brenam. Extracts were prepared of $200 \mathrm{~g}$ of fresh aerial parts and $100 \mathrm{~g}$ of dry aerial parts for each liter of distilled water resulting in the gross extract $(100 \%)$ diluted for the remainder concentrations $20,40,60$ and $80 \%$. The extract of Panicum maximum spoiled lettuce seed germination, however, the only effect on the native species studied was. Hence, the effect exerted on native species in this area cannot be allelopathyc incriminating other effects such as competition.
\end{abstract}

Keywords: allelopathy, Peltophorum dubium (Spreng.) Taub, Parapiptadenia rigida (Benth.) Brenam. 


\section{INTRODUÇÃO}

O Parque Nacional do Iguaçu abrange um dos poucos remanescentes florestais de Floresta Atlântica, por isso foi tombado pela Unesco como patrimônio natural da humanidade (Instituto..., 2006). A Estrada do Colono, construída cortando o parque, colocou em risco este título, pois causou vários danos ao ambiente florestal (Ambientebrasil, 2006). Devido a isso a estrada foi fechada por pressão de ambientalistas.

Mesmo com o fechamento da Estrada do Colono, ainda há sequelas. A vegetação secundária encontra dificuldade de regeneração. Um dos diversos fatores responsáveis pela inibição da sucessão ecológica é a invasão do local por espécies vegetais exóticas. Espécies exóticas são aquelas que ocorrem fora de seu limite natural e são potencialmente invasoras quando se adaptam ao ambiente ocupando o espaço de espécies nativas, resultando em grande proliferação (Ziller, 2000; Espíndola et al., 2005).

Gramíneas africanas são espécies invasoras em potencial, grandes responsáveis por contaminações biológicas. Entre elas está o capim colonião (Panicum maximum Jacq.), espécie altamente infestante e principal invasora da área da Estrada do Colono, no Parque Nacional do Iguaçu, que age impedindo a reestruturação ambiental (Carvalho \& Jacobison, 2005; Espíndola et al., 2005 ).

Um dos fatores responsável pela dominância de uma espécie no ambiente, a alelopatia, pode ser que seja exercida pelo capim sobre as espécies nativas do banco de sementes da Estrada do Colono. A alelopatia é a interferência de uma espécie sobre outra, a qual pode ser estimulante ou inibidora; baseia-se na liberação de compostos químicos, provenientes de metabolismo secundário, que agem isoladamente ou em conjunto (Rice, 1977; Taiz \& Zeiger, 2009; Raven et al., 2007).

Com o avanço da química, o estudo de substâncias aleloquímicas de espécies vegetais pode resultar no isolamento do princípio ativo (Ferreira \& Borguetti, 2004). Estes compostos revelam-se como herbicidas naturais, os quais estariam livres dos efeitos prejudiciais causados pelos herbicidas sintéticos (Yunes \& Calixto, 2001). Ou mesmo a utilização do extrato como agrotóxico, dependendo do grau de fitotoxidade.

Dessa forma, para verificar a influência do capim colonião (Panicum maximum Jacq.) foi testado seu extrato sobre sementes de alface e, posteriormente, sobre a germinação de duas espécies nativas, a canafístula (Peltophorum dubium (Spreng.) Taub) e $\mathrm{o}$ angico (Parapiptadenia rigida (Benth.) Brenam).

\section{MATERIAL E MÉTODOS}

Os experimentos foram conduzidos no Laboratório de Fisiologia Vegetal da Universidade Estadual do Oeste do Paraná (UNIOESTE), campus de Cascavel, no período de abril a outubro de 2006. As sementes de canafístula e angico foram doadas pela Fundação para Desenvolvimento Científico e Tecnológico (FUNDETEC) e Refúgio Biológico Itaipu, respectivamente.

Para identificar a potencialidade alelopática do capim colonião, foi testado extrato de folhas frescas e secas da espécie, sobre sementes de alface, que é uma espécie utilizada como bioindicadora por sua sensibilidade a aleloquímicos. O extrato de folhas mais influente foi escolhido e foi também testada a influência sobre sementes de espécies nativas de floresta semidecídua (característica da região da Estrada do Colono), a canafístula e o angico.

O extrato bruto foi obtido a partir da trituração de $200 \mathrm{~g}$ de folhas frescas ou $100 \mathrm{~g}$ de folhas secas (secagem em ambiente natural) com $1 \mathrm{~L}$ de água destilada (extrato a 100\%) e, a partir deste, foram feitas diluições nas concentrações de $0,20,40,60$, $80 \%$. Após a confecção do extrato foi determinado seu $\mathrm{pH}$.

Para sementes de alface, foram testados extratos de folhas frescas e secas e para sementes de espécies nativas, apenas extratos de folhas frescas.

$\mathrm{O}$ experimento foi realizado em duas etapas. $\mathrm{Na}$ primeira, avaliaram-se os efeitos do extrato de capim colonião sobre a germinação de alface, em que foi verificada a presença de aleloquímicos no capim colonião. $\mathrm{Na}$ segunda etapa, o extrato aquoso de capim colonião foi testado sobre as espécies nativas canafístula e angico.

Os ensaios ficaram acondicionados em câmara de germinação, com temperatura a $25^{\circ} \mathrm{C}+2{ }^{\circ} \mathrm{C}$ e 
fotoperíodo de 12 horas. As sementes de alface foram dispostas em placas de Petri, com três folhas de papel filtro usadas como substrato. As sementes de canafístula e de angico foram dispostas em papel germitest, sobre duas folhas e com uma folha por cima, em forma de rolo. Ambos os substratos foram previamente autoclavados a $121^{\circ} \mathrm{C}$ por 20 minutos. Os substratos foram umedecidos com o respectivo extrato 2,5 vezes o peso do papel.

As avaliações foram realizadas diariamente durante sete dias, considerando-se como semente germinada aquela que apresentou radícula com aproximadamente $2 \mathrm{~mm}$ de comprimento (Hadas, 1976). Além disso, foi medido comprimento de radícula das plântulas no final do experimento.

$\mathrm{O}$ delineamento experimental foi inteiramente casualizado (DIC), com quatro repetições. Os dados obtidos foram submetidos à análise de variância (teste F), utilizando-se a transformação arco seno da raiz quadrada da porcentagem, sendo as médias comparadas com o teste Tukey a $5 \%$ de probabilidade (Pimentel Gomes, 1990). Além disso, foram utilizadas observações quanto ao tempo médio de germinação calculado segundo Edmond \& Drapalla (1958) e a velocidade média de germinação calculada de acordo com Labouriau (1983).

\section{RESULTADOS E DISCUSSÃO}

$\mathrm{O}$ valor de $\mathrm{pH}$ para o extrato aquoso de capim colonião foi de 6,07 para o extrato fresco e 6,52 para extrato seco. A medida encontrada para os valores de
pH dos extratos está próxima da neutralidade, fato este que demonstra que este parâmetro provavelmente não interferiu no processo de germinação. Visto que informações disponíveis mostram que tanto a germinação como o desenvolvimento de plantas são afetados negativamente apenas em condições em que o meio ou é extremamente ácido ou extremamente alcalino (Souza Filho et al., 1997).

Segundo Ferreira \& Borguetti (2004), o controle do pH e da concentração dos extratos é fundamental, pois pode haver neles substâncias como açúcares, aminoácidos e ácidos orgânicos, os quais influem na concentração iônica e são osmoticamente ativos. Dessa forma, valores de $\mathrm{pH}$ próximos da neutralidade como encontrados neste trabalho, não devem interferir no processo de germinação.

A semente de alface é considerada bioindicadora da fitoxidade do extrato, podendo assim dar indicações importantes sobre o potencial alelopático. Segundo Ferreira e Aquila (2000), é uma das espécies mais sensíveis aos metabólitos secundários e por isso muito usada em biotestes em laboratório. Além disso, a resposta ao extrato é rápida devido ao seu baixo tempo de germinação.

O comprimento de raiz foi alterado: para a concentração de $20 \%$, foi reduzido pela metade, sendo maior o efeito quanto mais concentrado o extrato (Tabela 1). Isso indica interferência de capim colonião no desenvolvimento de alface. De acordo com Jacobi \& Ferreira (1991), a inibição do desenvolvimento, sob o ponto de vista ecológico, é forma de seleção que elimina a descendência.

Tabela 1. Efeito dos extratos de Panicum maximum Jacq. fresco e seco sobre a porcentagem de germinação (PG\%), tempo médio de germinação (TMG), velocidade média de germinação (VMG) e comprimento de radícula (CR) sobre sementes de Lactuca sativa.

Table 1. Effect of the extracts of Panicum maximum Jacq. fresh and dry on the percentage germination (PG\%) average time of germination (ATG), average speed of germination (ASG) and radicle length (RL) on seeds of Lactuca sativa.

\begin{tabular}{|c|c|c|c|c|c|c|c|c|}
\hline \multirow{2}{*}{ (\%) } & \multicolumn{4}{|c|}{ Extrato fresco } & \multicolumn{4}{|c|}{ Extrato seco } \\
\hline & PG\% & TMG & VMG & $\mathrm{CR}(\mathrm{cm})$ & PG\% & TMG & VMG & $\mathrm{CR}(\mathrm{cm})$ \\
\hline Testemunha & $94^{\mathrm{a}}$ & $1,37^{\mathrm{b}}$ & $0,72^{\mathrm{a}}$ & $3,37^{\mathrm{a}}$ & $94^{\mathrm{a}}$ & $1,37^{\mathrm{c}}$ & $0,72^{\mathrm{a}}$ & $3,37^{\mathrm{a}}$ \\
\hline 20 & $77^{b}$ & $1,54^{\mathrm{b}}$ & $0,64^{a}$ & $1,78^{\mathrm{b}}$ & $85^{a}$ & $1,51^{\mathrm{c}}$ & $0,65^{\mathrm{a}}$ & $3,26^{\mathrm{a}}$ \\
\hline 40 & $74^{\mathrm{b}}$ & $2,04^{\mathrm{b}}$ & $0,49^{\mathrm{b}}$ & $0,64^{\mathrm{c}}$ & $83^{\mathrm{a}}$ & $1,62^{\mathrm{bc}}$ & $0,61^{\mathrm{a}}$ & $2,84^{\mathrm{abc}}$ \\
\hline 60 & $72^{\mathrm{b}}$ & $2,72^{\mathrm{a}}$ & $0,37^{b c}$ & $0,34^{\text {cd }}$ & $85^{\mathrm{a}}$ & $2,07^{\mathrm{b}}$ & $0,48^{\mathrm{b}}$ & $2,85^{\mathrm{ab}}$ \\
\hline 80 & $38^{c}$ & $3,11^{\mathrm{a}}$ & $0,32^{\mathrm{c}}$ & $0,23^{\mathrm{cd}}$ & $85^{\mathrm{a}}$ & $2,07^{\mathrm{b}}$ & $0,48^{\mathrm{b}}$ & $2,23^{b c}$ \\
\hline 100 & $0^{\mathrm{d}}$ & - & - & - & $65^{\mathrm{a}}$ & $2,57^{\mathrm{a}}$ & $0,38^{\mathrm{b}}$ & $1,98^{\mathrm{c}}$ \\
\hline
\end{tabular}

Médias seguidas de mesma letra não diferem significativamente entre si pelo teste de Tukey, a 5\% de probabilidade. 
Tempo e velocidade médios foram afetados com o extrato fresco, comprovando a afirmação de Ferreira \& Borguetti (2004) de que a alelopatia influencia primeiramente na germinação, porém o crescimento da plântula é mais sensível aos aleloquímicos, podendo afetar a velocidade e o tempo de germinação, ou mesmo, causar raízes necrosadas ou plântulas anormais.

A alelopatia pode fazer com que uma espécie diminua a velocidade de germinação de outras e, se o desenvolvimento das outras espécies é prejudicado, a espécie favorecida pode estabelecer sua prole, evitando a pressão de competição. Conforme Ferreira \& Borguetti (2004), mesmo germinando, muitas vezes a plântula não consegue vencer as interferências e se instalar.

$\mathrm{Na}$ concentração de $100 \%$ de extrato fresco, a germinação foi inibida completamente; algumas sementes neste tratamento desenvolveram parte aérea, porém, como se segue o critério de Hadas (1976), não se considerou germinação e sim plântulas anormais.

Nas sementes de alface submetidas ao extrato fresco de capim colonião (Tabela 1), todos os parâmetros avaliados sofreram interferência em relação à testemunha, o que caracteriza possível efeito alelopático.

Neste trabalho, o extrato seco (Tabela 1) não apresentou diferença significativa para a porcentagem de germinação, porém, as sementes expostas às concentrações de 60,80 e $100 \%$ obtiveram menor velocidade de germinação e, consequentemente, levaram mais tempo para germinar. Se o desenvolvimento das outras espécies é prejudicado, a espécie favorecida pode estabelecer sua prole, evitando a pressão de competição.

O comprimento de raiz diminuiu conforme o aumento da concentração de extrato. Kissmann (1997) afirma que as plantas de Panicum maximum liberam compostos com ação alelopática e que o extrato aquoso de folhas secas contém ácido o-hidroxifenilacético e podem acumular grande quantidade de glucosídeos cianogênicos nas inflorescências, com efeito tóxico muito rápido.

Tendo em vista que a aplicação do extrato aquoso fresco de capim colonião sobre sementes de alface apresentou efeito mais pronunciado, o que indica provável presença de aleloquímicos, este foi aplicado sobre as espécies nativas.

A aplicação do extrato de capim colonião sobre as sementes de canafístula e angico não afetou os fatores avaliados, o único efeito encontrado foi o estimulatório para canafístula. Observa-se que no comprimento da radícula de canafístula (Tabela 2) a testemunha apresentou o valor de $2,03 \mathrm{~cm}$ e as sementes submetidas aos extratos, em todas as concentrações, passaram de $5,5 \mathrm{~cm}$, o que pode indicar influência positiva do capim colonião sobre o desenvolvimento da espécie. O comprimento de raiz de angico não foi afetado (Tabela 3). Estes resultados confirmam a definição de alelopatia, que diz que os efeitos podem ser benéficos ou prejudiciais.

Os parâmetros de porcentagem, tempo médio e velocidade média de germinação não foram afetados em relação à testemunha, tanto para sementes de canafístula como para de angico, não apresentando diferença estatística entre os tratamentos (Tabelas 2 e 3).

Scherer et al. (2005) estudaram o efeito de folhas e frutos de leucena sobre a germinação de canafístula, constataram que o extrato de folhas interferiu na porcentagem de germinação e comprimento de raiz na concentração de $100 \%$. O extrato do fruto mostrou maior potencial inibidor para sementes de canafístula. Assim, mesmo o capim colonião sendo uma espécie também exótica, os resultados obtidos no presente trabalho, apresentaram-se positivos sobre a germinação de canafístula, diferente dos resultados alcançados pelos autores acima, demonstrando que a resposta é diferente aos aleloquímicos de diferentes espécies.

De acordo com Goetze \& Thomé (2004), os processos utilizados para demonstrar que determinados extratos têm efeitos alelopáticos, não prova mais do que a existência de aleloquímicos no material vegetal, não podendo inferir que em condições de campo elas se manifestem, demonstrando a necessidade de estudos mais aprofundados. Lembrando que, no ambiente, o efeito pode se mostrar de diferente intensidade aos de testes de laboratório.

Tendo em vista o efeito observado dos extratos aquosos de material fresco e seco de capim colonião sobre sementes de canafístula e angico, admite-se 
Tabela 2. Porcentagem de germinação (PG\%), tempo médio de germinação (TMG), velocidade média de germinação (VMG) e comprimento da radícula (CR) de Peltophorum dubium submetido a concentrações do extrato de Panicum maximum.

Table 2. Percentage germination (PG\%), average time of germination (ATG), average speed of germination (ASG) and radicle length (RL) from Peltophorum dubium subjected to concentrations of extract of Panicum maximum.

\begin{tabular}{|ccccc|}
\hline Tratamento (\%) & PG\% & TMG & VMG & CR (cm) \\
\hline Testemunha & $83^{\mathrm{a}}$ & $2,60^{\mathrm{a}}$ & $0,38^{\mathrm{a}}$ & $2,03^{\mathrm{b}}$ \\
\hline 20 & $83^{\mathrm{a}}$ & $2,67^{\mathrm{a}}$ & $0,37^{\mathrm{a}}$ & $6,46^{\mathrm{a}}$ \\
\hline 40 & $83^{\mathrm{a}}$ & $2,76^{\mathrm{a}}$ & $0,36^{\mathrm{a}}$ & $5,73^{\mathrm{a}}$ \\
\hline 80 & $80^{\mathrm{a}}$ & $2,64^{\mathrm{a}}$ & $0,37^{\mathrm{a}}$ & $6,22^{\mathrm{a}}$ \\
\hline 100 & $87^{\mathrm{a}}$ & $2,82^{\mathrm{a}}$ & $0,35^{\mathrm{a}}$ & $5,74^{\mathrm{a}}$ \\
\hline
\end{tabular}

Médias seguidas de mesma letra não diferem significativamente entre si pelo teste de Tukey, a 5\% de probabilidade.

Tabela 3. Efeito dos extratos de Panicum maximum Jacq. fresco sobre a porcentagem de germinação (PG\%), tempo médio de germinação (TMG), velocidade média de germinação (VMG) e comprimento de radícula (CR) sobre sementes de Parapiptadenia rigida.

Table 3. Effect of the extracts of Panicum maximum Jacq. fresh on the percentage germination (PG\%), average time germination (ATG), average speed of germination (ASG) and radicle length (RL) on seeds of Parapiptadenia rigida.

\begin{tabular}{ccccc|}
\hline Tratamento (\%) & PG \% & TMG & VMG & CR(cm) \\
\hline Testemunha & $68^{\mathrm{a}}$ & $3,02^{\mathrm{a}}$ & $0,33^{\mathrm{a}}$ & $3,35^{\mathrm{a}}$ \\
\hline 20 & $67^{\mathrm{a}}$ & $2,57^{\mathrm{a}}$ & $0,38^{\mathrm{a}}$ & $3,99^{\mathrm{a}}$ \\
\hline 40 & $67^{\mathrm{a}}$ & $2,43^{\mathrm{a}}$ & $0,41^{\mathrm{a}}$ & $3,34^{\mathrm{a}}$ \\
60 & $57^{\mathrm{a}}$ & $2,44^{\mathrm{a}}$ & $0,40^{\mathrm{a}}$ & $2,84^{\mathrm{a}}$ \\
\hline 80 & $72^{\mathrm{a}}$ & $2,74^{\mathrm{a}}$ & $0,36^{\mathrm{a}}$ & $3,39^{\mathrm{a}}$ \\
\hline 100 & $66^{\mathrm{a}}$ & $2,68^{\mathrm{a}}$ & $0,37^{\mathrm{a}}$ & $3,15^{\mathrm{a}}$ \\
\hline
\end{tabular}

Médias seguidas de mesma letra não diferem significativamente entre si pelo teste de Tukey, a $5 \%$ de probabilidade.

que o capim colonião não causou efeito negativo sobre as espécies estudadas. Esse fato demonstra que, provavelmente, a interferência que o capim colonião tem na Estrada do Colono sobre essas espécies não deve ser devido à presença e liberação de aleloquímicos, pode-se dever a outros fatores como competição por recursos naturais. Lembrando que as informações científicas sobre a alelopatia do gênero Panicum são escassas, fica demonstrada a necessidade de estudos a respeito.

\section{CONCLUSÕES}

Nas condições em que foram realizados os experimentos, o capim colonião apresentou interferência alelopática sobre sementes de alface, causando efeito inibitório; porém não foi observada a mesma resposta nas sementes de espécies nativas canafístula e angico, visto que o único efeito significativo observado foi estimulatório.

\section{STATUS DA SUBMISSÃO}

Recebido: 16/03/2010

Aceito: $17 / 06 / 2011$

Resumo publicado online: 25/06/2011

Artigo completo publicado: 30/06/2011

\section{AUTOR(ES) PARA CORRESPONDÊNCIA}

\section{Danielle Medina Rosa}

Universidade Estadual do Oeste do Paraná UNIOESTE, Rua Odontologia, 820, CEP 85819-220, Cascavel, PR, Brasil e-mail: danimrosa@yahoo.com.br

\section{Andréa Maria Teixeira Fortes}

Universidade Estadual do Oeste do Paraná UNIOESTE, Rua Universitária, 2069, CEP 85819-110, Cascavel, PR, Brasil e-mail: amtfortes@unioeste.br 


\section{REFERENNCIAS}

Ambientebrasil. Estrada do Colono. 2006. [cited 2006 jul. 4]. Available from: http://www.ambientebrasil. com.br/composer.php3 ? base =./natural/index. html\&conteudo=./natural/artigos/ecolono.html.

Carvalho FA, Jacobison TKB. Invasão de plantas daninhas no Brasil - uma abordagem ecológica. In: Anais do Simpósio brasileiro sobre espécies exóticas invasoras; 2005; Brasília. Brasília: MMA; 2005. [cited 2006 jun. 29]. Available from: www.mma.gov.br/ invasoras/capa/doc/painéis.pdf.

Edmond JB, Drapalla WJ. The effects of temperature, sana and soil, and acetone on germination oj okra seed. Proceedings of the American society for horticuticultural Science 1958; 71:428-443.

Espíndola MB, Bechara CB, Bazzo MS, Reis A. Recuperação ambiental e contaminação biológica: aspectos ecológicos e legais. Biotemas 2005; 18(1):27-38.

Ferreira A, Aquila MA. Alelopatia: uma área emergente da ecofisiologia. Revista Brasileira de Fisiologia Vegetal 2000; 12(edição especial):175-204.

Ferreira AG, Borguetti F. Germinação: do básico ao aplicado. Porto Alegre: Ed. Artmed; 2004. 222 p.

Goetze M, Thomé GCH. Efeito alelopático de extratos de Nicotiana tabacum e Eucalyptus grandis sobre a germinação de três espécies de hortaliças. Revista Brasileira de Agrociência 2004; 10(1):43-50.

Hadas A. Water update germination of leguminous seeds under changing external water potential in osmotic solution. Journal of Experimental Botany 1976; 27.

Instituto Brasileiro do Meio Ambiente e dos Recursos Naturais Renováveis - IBAMA. Parque Nacional do
Iguaçu. [cited 2006 jul. 4]. Available from: http://www. ibama.gov.br/parna_iguaçu.

Jacobi US, Ferreira AG. Efeitos alelopáticos de Mimosa bimunocrata (DC) OK sobre espécies cultivadas. Pesquisa Agropecuária Brasileira 1991; 26(7):935-943.

Kissmann KG. Plantas infestantes e nocivas. 2rd ed. São Paulo: Basf; 1997. 649 p.

Labouriau LG. A germinação de sementes. Washington: Organização dos Estados Americanos; 1983.

Pimentel Gomes F. Curso de estatística experimental. São Paulo: Nobel; 1990.

Raven P, Evert RF, Eichhorn SE. Biologia Vegetal. Rio de Janeiro: Editora Guanabara Koogan; 2007.

Rice EL. Some roles of allelopathic compounds in plant communities. Biochemical Systematics and Ecology 1977; 201-206.

Scherer LM, Zucareli V, Zucareli CA, Fortes AMT. Efeito alelopático do extrato aquoso de folha e de fruto de leucena (Leucaena leucocephala Wit) sobre a germinação e crescimento de raiz de canafístula (Peltophorum dubium Spreng.). Semina: Ciências Agrárias 2005; 26(2):153-158.

Souza Filho APS, Rodrigues LR, Rodrigues TJ. Efeitos do potencial alelopático de três leguminosas forrageiras sobre três invasoras de pastagens. Pesquisa Agropecuária Brasileira 1997; 32(2):165-170.

Taiz L, Zeiger E. Fisiologia vegetal. 3rd ed. Porto Alegre: Editora Artmed; 2009. 819 p.

Yunes RA, Calixto JB. Plantas medicinais sob a ótica da moderna química medicinal. Chapecó: Argos; 2001.

Ziller SR. Plantas exóticas invasoras: a ameaça da contaminação biológica. Revista Ciência Hoje 2000; 30(178). 